\title{
ORAÇÕES TEMPORAIS COM VALOR CONDICIONAL NA LINGUAGEM LEGAL (ESTUDO CONTRASTIVO)
}

\author{
ORACIONES TEMPORALES CON VALOR CONDICIONAL EN EL LENGUAJE LEGAL \\ (ESTUDO CONTRASTIVO)
}
TEMPORAL CLAUSES WITH CONDITIONAL VALUE IN LEGAL LANGUAGE (CONTRASTIVE STUDY)

Iva Svobodová*

Faculdade de Letras da Universidade de Masaryk | República Tcheca

\begin{abstract}
RESUMO: O presente estudo apresenta os principais resultados de uma análise linguística quanti-qualitativa dos Códigos Penais de Portugal e do Brasil, relativos às orações temporais introduzidas por quando utilizadas nos seus textos. $\mathrm{O}$ alvo do nosso interesse são as propriedades condicionais destas construções hipotáticas, que sugerimos serem denominadas como pseudo-temporais. Ao mesmo tempo, observamos a relação existente entre a seleção dos modos verbais dos seus predicados e a sua interpretação semântica. O nosso estudo mostrou que ambos os textos coincidem no sentido de as orações temporais introduzidas por quando possuírem um evidente valor condicional. Por outro lado, no entanto, verificou-se haver tendências divergentes no que à seleção dos modos verbais diz respeito, sendo no Código Penal de Portugal, preferido, univocamente, o uso do modo conjuntivo e, no Código Penal do Brasil, ao contrário, o indicativo. Propomos explicar esta divergência por fatores semântico-pragmáticos.
\end{abstract}

PALAVRAS-CHAVE: Orações pseudo-temporais. Linguagem legal. Modo verbal.

RESUMEN: El presente artículo resume los principales resultados del análisis lingüístico cuantitativo y cualitativo de los Códigos Penales de Portugal y del Brasil, relacionados con las oraciones temporales que son introducidas por el conector temporal quando, ocurridas en los textos referidos. Prestamos atención al hecho de que estas oraciones ganan rasgos semánticos típicos de las oraciones condicionales, sugiriendo denominarlas como pseudo-temporales. Al mismo tiempo, es nuestro objetivo observar la relación que hay entre los modos verbales en los que se encuentran los predicados de estas oraciones y su interpretación semántica. Nuestro estudio ha mostrado que, por un lado, los textos comparados concuerdan en lo que se refiere a la interpretación condicional de las oraciones introducidas por quando, pero, por otro lado, difieren en lo que atañe a la distribución modotemporal, siendo en el Código Penal de Portugal, preferido, unívocamente, el uso del modo subjuntivo y, en el Código Penal del Brasil, al contrario, el indicativo. Proponemos explicar esta diferencia por factores semántico-pragmáticos.

PALABRAS CLAVE: Oraciones pseudo-temporales. Lenguaje legal. Modo verbal.

ABSTRACT: This study is a summary of a qualitative and quantitative linguistic investigation of the Portuguese and Brazilian Penal Code, and contains important results pertaining to the temporal clauses introduced by the connector quando. We focused on its

\footnotetext{
* Em 2008 , doutorou-se em Filologia das Línguas Românicas na Universidade Carolina em Praga, na República Tcheca. Hoje é professora associada de Língua e Linguística Portuguesas na Faculdade de Letras da Universidade de Masaryk, em Brno, na República Tcheca E-mail:9255@mail.muni.cz; página pessoal: https://www.muni.cz/en/people/9255-iva-svobodova ou https://www.researchgate.net/profile/Iva_Svobodova.
} 
semantic conditional features, suggesting the name pseudo-temporal clauses for these hypotactic constructions and observe the relation between the occurrence of different verbal modes and the semantic interpretation. We verify, in both the texts, the temporal clauses introduced by quando have an evident conditional value. On the other side, the compared texts are different regarding the selection of the verbal mode. The Portuguese Penal Code preferred, evidently, the subjunctive mode and in the Brazilian one the indicative mode. We explained this divergence by semantic and pragmatic factors.

KEYWORDS: Pseudo-temporal clause. Legal language. Verbal mode.

\section{INTRODUÇÃO}

O presente $\operatorname{artigo~}^{1}$ tem por objetivo apresentar os resultados de uma pesquisa linguística realizada na área da sintaxe e semântica relacionada com as orações temporais introduzidas por quando utilizadas nas versões atualizadas dos Códigos Penais Português e Brasileiro, doravante designados como $\mathrm{CPP}$ e $\mathrm{CPB}^{2}$, respetivamente. $\mathrm{O}$ aspecto que iremos desenvolver no presente artigo é interessante, sobretudo, desde dois pontos de vista: o semântico e o morfo-semântico. Relativamente ao primeiro aspecto, o semântico, refletiremos sobre o verdadeiro significado de quando e tentaremos provar que este conetor adverbial temporal ganha um valor condicional nos textos por nós estudados. Relativamente ao segundo fator, o morfo-semântico, serão observadas as diferenças e coincidências existentes entre os dois Códigos no que diz respeito ao uso dos diferentes modos verbais.

\section{ENQUADRAMENTO TEÓRICO}

A conjunção quando, por mais tipicamente temporal que seja, não o é em todos os contextos, diferindo das que poderiam ser consideradas como exclusivamente temporais (como são, por exemplo, antes que, depois que, logo que, até que) pelo fato de veicular também um sentido condicional. Neste sentido, o presente estudo refletirá sobre o seu valor na linguagem legal, concretamente, nos Códigos Penais, em que a sua natureza semântica apresenta traços semânticos semelhantes aos que são típicos do conetor se.

Deparamo-nos sobretudo com situações nas quais a oração temporal tem uma interpretação genérica, como exemplificam os exemplos 2 e 3, em que a proposição da oração subordinada apresenta um caráter repetitivo, gnômico ou habitual, cedendo o traço de temporalidade e destacando-se o traço de condicionalidade (HIRATA, 2005, p.1204). Nestes casos, quando poderia ser substituído por sempre que, todas as vezes que, cada vez que, que igualmente exprimem a chamada quantificação temporal sobre situações de natureza plural, implicando ou o valor periódico e genérico factual (exemplos 4 a 5) com o predicado no modo indicativo, ou o valor repetitivo hipotético, exemplificado pela frase 6 com o predicado no modo conjuntivo ${ }^{3}$.

(1) Se a água atinge a temperatura de $100^{\circ} \mathrm{C}$, começa a ferver.

(2) Quando a água atinge a temperatura de $100^{\circ} \mathrm{C}$, começa a ferver.

(3) Quando uma criança não quer comer, é mau sinal.

(4) Sempre que vou a Portugal, visito a minha amiga Cristina.

(5) O Pedro canta a Canção do Mar (de) cada vez que lhe pedem.

(6) Sempre que quiseres, telefona-me.

\footnotetext{
${ }^{1}$ Este artigo é fruto de tese de agregação ainda não publicada, cujo tema central (análise linguística dos Códigos Penais dos dois países) foi escolhido por vários motivos. A razão principal foi contribuir para estudos de tradutologia oficial, já que foi verificada uma tendência crescente de processos penais correntes com participantes lusofalantes no nosso país e, portanto, um estudo que analise as diferenças linguísticas existentes entre os textos jurídicos escritos em duas diferentes variedades da língua portuguesa poderia ser útil aos tradutores e intérpretes. Ao mesmo tempo, o objeto do nosso trabalho pertence à área de linguística forense, que procura, sobretudo, analisar as relações existentes entre a Linguagem, a Lei e o Direito. Para além destes motivos, pretendemos contribuir, com a nossa tese, para a área de linguística contrastiva, mostrando as divergentes e convergentes propriedades das orações condicionais em Português Europeu e Brasileiro no nível mais geral, que se sobrepõe ao nível da linguagem jurídica.
}

${ }^{2}$ Para a análise foram utilizadas as versões atualizadas dos Códigos penais de ambos os países.

${ }^{3}$ Os exemplos citados entre 2 e 6 só ilustram o uso no Português Europeu. 
Ao contrário, nas frases 7 e 8, que ilustram o uso em PE, quando implica o valor restritamente temporal (RAPOSO et al., 2013) veiculando a relação de sobreposição ou de posterioridade, podendo ser usado o predicado tanto no modo indicativo (nesse caso, $o$ seu valor modal é factual) como no modo conjuntivo (que tem um caráter hipotético).

Quando construíram a nova ponte, contrataram arquitectos de grande formato.

Quando o Rui melhorar, a Maria vai visitá-lo.

De acordo com Hirata (2005), às construções temporais com um valor condicional pertencem aquelas que contêm qualquer dos meios gramaticais que impliquem um caráter durativo, atélico, habitual ou gnômico verificando a autora cinco situações que favorecem a interpretação das frases temporais como temporais com o valor de condicional, que propomos denominar como pseudo-temporais. Estas situações dão-se quando:

1. o predicado da frase subordinada temporal $\mathrm{F}^{-}$está no presente do indicativo ( Quando são questionados a respeito de soluções, todos dizem, com a maior cara-de-pau, que estão investindo - "ao contrário do meu antecessor" - e que vão fazer uma revolução.») (HIRATA, 2005, p. 120);

2. o predicado da F- está no futuro do conjuntivo sendo usado no sentido atélico, repetitivo, habitual ou gnômico («Quando os brasileiros puderem ser mais informados, quando puderem ser mais críticos das políticas postas em prática do que do folclore dos fatos diversos da vida cotidiana, quando puderem pôr mais em perspectiva os acontecimentos e cobrar mais a coerência da ação do que fazer julgamentos de intenção, mais capacitados vão estar para o exercício da cidadania.» (HIRATA, 2005, p. 119);

3. o predicado da F- está no imperfeito do indicativo ( Quando me determinava a fechar os olhos, os restos de personalidade se atropelavam, fugiam, no fervedouro interno se agitavam confusões, a brasa do cigarro esmorecia, findava. Um sobressalto: necessário riscar outro fósforo.») (HIRATA, 2005, p. 123);

4. o predicado da F- está no pretérito perfeito simples sendo usado no sentido de quantificação plural («Podem culpá-los quando, ao tomar conhecimento de que as coisas ocorreram, não tomaram providencias no sentido da busca da responsabilidade.») (HIRATA, 2005, p. 123);

5. a oração temporal está introduzida pela locução conjuncional sempre que («Sempre que se pensa muito, acaba-se não casando!») (HIRATA, 2005, p. 122).

Depreenda-se que quando, nas situações em que possui um valor condicional, isto é, nas frases pseudo-temporais, poderia, teoricamente, seguir a mesma tipologia que se aplica ao caso das orações condicionais introduzidas por se. Conforme as classificações propostas por Peres, Moia e Marques (1999), Marques (1999, 2001, 2004, 2014), Lopes (2009), Roxo (2011) e Kratzer (1999), a tipologia das frases condicionais se assenta, em total, em três aspectos:

1. o modo verbal em que está o predicador da F- (que faz distinguir três tipos de condição: real, hipotética ou contrafactual);

2. o fator semântico-formal (segundo o qual as orações condicionais se dividem em monocondicionais e bicondicionais);

3. a base modal de todo o período (segundo a qual as orações condicionais se dividem em canônicas vs. não canônicas ou circunstanciais $v s$. epistêmicas).

De acordo com o primeiro aspecto, verificou-se que as orações introduzidas por quando podem exprimir apenas dois tipos da condição: a condição real (que corresponde à realidade descrita) e a hipotética (que pertence ao imaginário de situações potencionalemente realizáveis no momento futuro). No caso da condição contrafactual, como mostra o exemplo 11, marcado com o asterisco, o uso de quando resulta inaceitável, o que se deve ao fato de a oração em questão não implicar a quantificação plural sobre a situação e de não apresentar nenhuma das situações descritas por Hirata (2005).

Veja-se, para o efeito de comparação, os seguintes exemplos de PE e o quadro 1:

(9) Quando o Rui está doente, a mãe visita-o todos os dias.

(10) Quando o Rui estiver doente, a mãe vai visitá-lo todos os dias.

(11) ${ }^{*}$ Quando tivesses vindo cedo, terias jantado comigo. 
Condição na proposição da oração temporal com valor condicional

\begin{tabular}{c|r} 
real & hipotética \\
$($ frase 9) & $($ frase 10)
\end{tabular}

Quadro 1: Classificação das condições nas orações introduzidas por quando

No que se refere à tipologia consoante ao segundo aspecto mencionado, o semântico-formal, a substituição de se por quando resultou possível em todos os tipos, tal como expomos nas seguintes linhas.

Começando pela tipologia segundo Peres et al. (1999) e Marques (1999, 2000, 2001, 2014), existem dois tipos básicos das orações condicionais: monocondicionais e bicondicionais. Estes são divididos em vários subtipos, segundo o quadro 2 e de acordo com a teoria descrita debaixo desse:

\begin{tabular}{|c|c|c|c|c|}
\hline \multicolumn{3}{|c|}{ MONOCONDICIONAIS } & \multicolumn{2}{|c|}{ BICONDICIONAIS } \\
\hline \multicolumn{2}{|c|}{$\begin{array}{l}\text { COM MARCAÇÃO DA CONDIÇÃO } \\
\text { SUFICIENTE }\end{array}$} & \multirow{2}{*}{$\begin{array}{c}\text { COM } \\
\text { MARCAÇÃO DA } \\
\text { CONDIÇÃO } \\
\text { NECESSÁRIA (OU DE } \\
\text { CONDIÇÃO } \\
\text { NECESSÁRIA) }\end{array}$} & \multirow{2}{*}{ DIRETAS } & \multirow{2}{*}{ INDIRETA } \\
\hline $\begin{array}{l}\text { DE CONDIÇÃO } \\
\text { SUFICIENTE } \\
\text { FECHADA }\end{array}$ & $\begin{array}{c}\text { DE CONDIÇÃO } \\
\text { SUFICIENTE ABERTA (OU } \\
\text { INCONDICIONAIS) }\end{array}$ & & & \\
\hline
\end{tabular}

Quadro 2: Classificação das construções condicionais de acordo com o tipo de condição

Relativamente às orações monocondicionais, essas poderiam ser caraterizadas pela relação monodirecional existente entre as frases principal $\left(\mathrm{F}^{+}\right)$e subordinada $\left(\mathrm{F}^{-}\right)$, no sentido de a veracidade do antecedente influenciar a veracidade do consequente ${ }^{4}$, isto é, se o antecedente for verdadeiro, o consequente também o é, sendo a condição expressa pela oração subordinada de natureza chamada "suficiente". Esta dependência lógica funciona apenas num sentido, isto é, não pode ocorrer no sentido inverso, porque a veracidade do consequente não influencia a veracidade do antecedente. No entanto, destaque-se que só quando o caráter da proposição implica a quantificação plural, é possível a substituição de se por quando, caso que não se dá na frase 12, mas que pode ser exemplificado pelas frases 9 ou 10, como veremos mais adiante.

Se/ ${ }^{*}$ quando ${ }^{5}$ não chegarmos atrasados, deixam-nos entrar. (LOBO, 2013 apud RAPOSO, 2013, p. 2022)

Do exemplo 12, que ilustra o uso em PE, Lobo (2013) infere que se chegarmos atrasados, provavelmente, não nos deixarão entrar, sendo, no entanto, possível a versão oposta, isto é, poderemos ainda assim, ter a sorte de nos deixarem entrar. Assim, a autora interpreta a condição de não chegar atrasado como uma condição suficiente, mas não necessária para a veracidade da frase $\mathrm{F}^{+}$, tal como visualiza o esquema 1 :

${ }^{4}$ Os termos antecedente e consequente são habitualmente utilizados pelos autores para designarem a frase condicional (prótase) e principal (apódose), respetivamente.

${ }^{5}$ A inclusão da conjunção quando é da responsabilidade da autora, visando mostrar a inaceitabilidade de substituição (quando a proposição não implica uma quantificação plural) e não faz parte da versão original do exemplo citado. 
Esquema 1: Orações monocondicionais "monodirecionais"

$\begin{array}{cc}\text { Condição da frase subordinada } & \text { Proposição da frase principal (2 leituras) } \\ \begin{array}{cc}\text { condição suficiente } & \text { 1. poderão deixar-nos entrar } \\ \text { (chegar atrasado) } & \text { 2. poderão não nos deixar entrar }\end{array}\end{array}$

Cálculo proposicional: $[\mathrm{p} \rightarrow \mathrm{q}]$

Neste caso, a direção em que decorre a dedução possível se dá num sentido, não podendo ser admitida a equivalência de veracidade entre $\mathrm{F}^{+}$e F- Esta implicaria a situação em que só nos deixariam entrar se não chegássemos atrasados.

A mesma interpretação está patente também na frase 10: «Se/quando o Rui estiver doente, a mãe vai visitá-lo todos os dias.», em que poderá haver tanto as situações em que a mãe irá visitar o filho todos os dias, como, também, dias em que, por circunstâncias dadas no momento da proposição da $\mathrm{F}^{-}$, tal não será possível.

As orações monocondicionais de condição suficiente podem ainda ser subdivididas em orações de condição suficiente fechada (frase 3) e de condição suficiente aberta - as denominadas “incondicionais” conforme Zaefferer (1991 apud MARQUES, 2014, p. 113), tradicionalmente classificadas como concessivas (frase 13). Como os dados do corpus Linguateca (SANTOS, 2017) e dos seus subcorpora CETENFolha ${ }^{6}$ e CETEMPublico ${ }^{7}$ provam, a ocorrência de quando neste tipo de orações é possível, embora seja mais habitual o seu uso com o predicado no modo indicativo (frase 14) do que com o conjuntivo (frase 15) - as frases 14 e 15, copiadas do corpus CETENFolnha, documentam o uso em PB.

(13) O Paulo sai, mesmo se/?mesmo quando ${ }^{8}$ chover. (MARQUES, 2014, p. 113)

(14) Saldanha dizia que as reuniões eram problemáticas porque todos são surdos, e cada tema leva horas para ser discutido, e assim mesmo quando é ouvido. (SANTOS, 2017)

(15) Como a Folha já informou ontem, há no PSDB a intenção de preservar ao máximo a figura de Lula, mesmo quando for necessário fazer críticas duras ao PT. (SANTOS, 2017)

Relativamente às orações de condição necessária (frase 16), não só a verdade do antecedente determina a verdade do consequente, mas também a verdade do antecedente é assegurada pela verdade do consequente, sendo a condição expressa pela oração subordinada tanto suficiente como necessária, destacada ainda pelo elemento só, somente ou apenas, que restringe o mundo dos possíveis condicionantes a uma condição explícita na frase subordinada (LOBO, 2013 apud RAPOSO, 2013, p. 2022). Neste caso, o uso de quando seria natural, tal como exemplifica a frase 16, que ilustra o uso em PE.

Só te vais curar, se/ quando ${ }^{9}$ deixares de fumar. (MARQUES, 2014)

${ }^{6}$ CETENFolha (Corpus de Extractos de Textos Electrónicos NILC/Folha de S. Paulo) é um corpus de cerca de 24 milhões de palavras em português brasileiro, criado pelo projeto Processamento computacional do português com base nos textos do jornal Folha de S. Paulo, que fazem parte do corpus NILC/São Carlos, compilado pelo Núcleo Interinstitucional de Lingüística Computacional (NILC).

${ }^{7}$ O CETEMPúblico (Corpus de Extractos de Textos Electrónicos MCT/Público) é um corpus de aproximadamente 180 milhões de palavras em português europeu, criado pelo projeto Processamento computacional do português após a assinatura de um protocolo entre o Ministério da Ciência e da Tecnologia (MCT) português e o jornal PÚBLICO, em abril de 2000.

${ }^{8}$ A inclusão de quando é também da responsabilidade da autora, visando mostrar a eventual substituição de se por quando, mas com um reduzido grau de aceitabilidade, sinalizado pelo ponto de interrogação. Quando não faz parte da versão original do exemplo citado.

${ }^{9} \mathrm{~A}$ inclusão da conjunção quando é também da responsabilidade da autora, visando mostrar a eventual substituição e não faz parte da versão original do exemplo citado. 
Esquema 2: Orações com condição necessária

Condição da frase principal

proposição C

(curar-se)
Proposição da frase subordinada

proposição D

(deixar de fumar)

Cálculo proposicional: $[\mathrm{C} \rightarrow \mathrm{D}]$ equivalente $\mathrm{a}[\neg \mathrm{C} \rightarrow \neg \mathrm{D}]$ mas não equivalente $\mathrm{a}[\mathrm{D} \rightarrow \mathrm{C}]$

Quanto às orações bicondicionais, a relação existente entre o antecedente e o consequente é bidirecional ou mútua, o que significa que não só a verdade do antecedente determina a verdade do consequente, mas também a verdade do antecedente é assegurada pela verdade do consequente, sendo a condição expressa pela oração subordinada tanto suficiente como necessária. Isto significa que as proposições de ambas as orações possuem o mesmo valor de verdade: ou ambos são verdadeiros ou ambos são falsos. Lobo (2013) menciona que as estruturas bicondicionais (de condição dupla, isto é, tanto suficiente como necessária) são introduzidas pelas conjunções ou locuções conjuncionais desde que, contanto que e a não ser que, como ilustra a seguinte frase 17.

$$
\text { Desde que/ ?quando }{ }^{10} \text { deixamos de fumar, vamos curar-nos. }
$$

Na frase 17, sabemos que se deixarmos de fumar, vamos curar-nos e, inversamente, sabemos que, se nos curarmos, é porque deixamos de fumar, o que significa que deixar de fumar é uma condição não só suficiente como também necessária para que nós nos curemos, tal como visualiza o seguinte esquema 3 :

Esquema 3: Orações bicondicionais

\author{
condição da frase subordinada \\ proposição D \\ (não chegar atrasado) \\ (chegar atrasado)
}

proposição da frase principal
proposição C
(deixar entrar $)$
(não deixar entrar $)$

Cálculo proposicional: $[\mathrm{p} \rightarrow \mathrm{q}$ ]

Lobo (2013), no entanto, alerta que, muitas vezes, os falantes nativos interpretam as orações monocondicionais de condição necessária como orações bicondicionais. Entre elas, no entanto, existe uma diferença marcante, que pode ser observada pelos esquemas 2 e 3, embora admitamos que na linguagem falada seja pouco transparente. É que, ao serem comparadas as frases 16 («Só te curas, se/quando deixares de fumar») e 17 («Desde que/quando® deixamos de fumar, vamos curar-nos.»), encontramos, de um ponto de vista semântico mais abstrato, dois valores diferentes (LOBO, 2013, p. 2024). Na frase 16, deixar de fumar é uma condição necessária para a cura, mas não é a condição suficiente. A cura pode, por exemplo, necessitar, também, de outros meios farmacológicos adequados, em cuja ausência a cura não terá sucesso. Na frase 17, no entanto, a cura é assegurada apenas pelo fato de se deixar de fumar, o que significa que deixar de fumar é uma condição não só necessária como também suficiente.

No que tange à capacidade de quando de substituir os conetores desde que, contanto que e a não ser que, que implicam esta dupla condição, em nossa perspetiva, tal seria reconhecida apenas naquelas frases que possuem um caráter gnômico e que transmitem verdades universais, prototipicamente apresentadas pela frase 2: «Quando a água atinge a temperatura de $100^{\circ} \mathrm{C}$, começa a ferver.», que contém tanto uma condição necessária, patente na sua seguinte versão ( «A água só começa a ferver se/quando atinge a

\footnotetext{
${ }^{10}$ Ver a nota de rodapé anterior.
} 
temperatura de $\left.100^{\circ} \mathrm{C} »\right)$, como a dupla condição, expressa na frase «A água começa a ferver desde que/quando atinja a temperatura de $100^{\circ} \mathrm{C}$ », em que o fato de a água começar a ferver se vê condicionado pela temperatura de ebulição, mas ao mesmo tempo, a temperatura de ebulição implica que a água começa a ferver.

Nesta linha da lógica, portanto, poderemos deduzir que se a água não atingir a dita temperatura, então ela não vai ferver. Num sentido oposto, se a água não ferve, então é porque não atingiu a temperatura necessária. Regressando à substituibilidade de quando neste tipo de orações bicondicionais, repare-se que, no caso da frase mencionada, a natureza dupla da condição parte do conhecimento geral relativo às leis da física. No entanto, em situações fora desta área de conhecimento, no âmbito de um uso corrente da língua, na nossa opinião, o uso de quando para exprimir a condição dupla não seria justificável.

Por sua vez, as construções bicondicionais são subdivididas em diretas e indiretas. Nas do primeiro tipo (frase 17), o operador de bicondicionalidade se aplica diretamente à proposição que traduz a oração subordinada, enquanto nas bicondicionais indiretas (frase 18), o operador de bicondicionalidade se aplica à contraditória da proposição, que traduz a oração subordinada da língua natural. Nestes contextos, a ocorrência de quando, segundo uma sondagem prévia, realizada nos corpora CETEMPúblico e CETENFolha, é também possível, embora menos frequente.

(18) Faremos a filmagem amanhã salvo se/salvo quando ${ }^{11}$ chover.

(19) Ninguém negará utilidade aos transplantes, à dissecção, aos testes, mas muitos os consideraram, salvo quando há doação esclarecida, eticamente inaceitáveis. (SANTOS, 2017)

(20) Não será permitida a apreensão de documento em poder do defensor do acusado, salvo quando constituir elemento do corpo de delito. (SANTOS, 2017)

Como se pode deduzir do dito, de acordo com esta tipologia, as orações introduzidas por quando apresentam a mesma variabilidade como as tipicamente condicionais, como mostra o quadro 3.

\begin{tabular}{|c|c|c|c|c|}
\hline \multicolumn{3}{|c|}{ MONOCONDICIONAIS } & \multicolumn{2}{|c|}{ BICONDICIONAIS } \\
\hline $\begin{array}{l}\text { COM MARCA } \\
\text { SUFICIENTE }\end{array}$ & ÃO DA CONDIÇÃO & $\begin{array}{l}\text { COM MARCAÇÃO DA } \\
\text { CONDIÇÃO }\end{array}$ & DIRETAS & INDIRETA \\
\hline DE CONDIÇÃO & CONDIÇÃO & NECESSÁRIA (OU DE & (FRASE 17) & (FRASES 18,19,20) \\
\hline SUFICIENTE & SUFICIENTE ABERTA (OU & CONDIÇÃO & & \\
\hline FECHADA & INCONDICIONAIS) & NECESSÁRIA) & & \\
\hline (FRASE 10) & (FRASES 13,14,15) & (FRASE 16) & & \\
\hline
\end{tabular}

Quadro 3: Proposta da classificação das construções pseudo-temporais com quando

A nossa hipótese é que, na linguagem legal, serão evitadas as construções bicondicionais ou as construções de condição necessária, devido a sua tendência de desinterpretabilidade semântica, que pode ser causada pelas restrições semânticas que implicam. Ao contrário, consideramos idôneo o uso das orações monocondicionais de condição fechada, que abrem um espaço para mais eventualidades intepretativas da proposição da frase subordinante (esquema 1), menos restritas e menos categóricas o que, por um lado, não é ideal ao considerarmos que a lei deveria ser unívoca, mas, por outro lado, é necessário para os crimes julgados poderem ser considerados e resolvidos com base em critérios individuais (agravantes e atenuantes) e não universais.

${ }^{11}$ Ver a nota de rodapé anterior. 
Podemos antecipar que os dados do gráfico 1 (da seção 3) confirmam a nossa hipótese, falando univocamente a favor das frases pseudo-temporais com o valor de condição suficiente (frase 21), sendo registadas, esporadicamente, também as ocorrências de condição necessária (frase 22) ou de bicondicionais indiretas (frase 23).

(21) Quando alguém tiver praticado vários crimes antes de transitar em julgado a condenação por qualquer deles é condenado numa única pena. (PORTUGAL, $1982^{12}$, Art. $77 \$ 1^{\circ}$ )

(22) Tratando-se de condenação a pena de prisão superior a 5 anos pela prática de crime contra as pessoas ou de crime de perigo comum, a liberdade condicional apenas poderá ter lugar quando se encontrarem cumpridos dois terços da pena e uma vez verificados os requisitos das alíneas a) e b) do nº 2. (PORTUGAL, 1982, Art. 61)

(23) Nos crimes previstos neste Capítulo somente se procede mediante queixa, salvo quando, no caso do art. 140 , $\$ 2^{\circ}$, da violência resulta lesão corporal. (BRASIL, $1940^{13}$, Art. 145)

De acordo com a terceira classificação das frases condicionais, baseada no valor de base modal veiculado pelas orações condicionais, ao levarmos em consideração todos os tipos estabelecidos por Lopes (2009), Marques (2014), Kratzer (2001) e Roxo (2011), a tipologia resulta num sistema mais complexo.

Segundo Lopes (2009, p.50), as orações condicionais são de dois tipos: 1. canônicas e 2. não canônicas. Enquanto o primeiro tipo pode ser descrito "num quadro estritamente semântico" (MARQUES, 2014, p. 115 apud LOPES, 2009, p. 150), a caraterização do segundo tipo “[...] envolve a tomada em consideração do plano pragmático-funcional da significação linguística” (MARQUES, 2014, p.115). No caso das orações não canônicas, em nossa opinião, a substituição por quando resulta muito ou pouco natural (mesmo quando o predicado é atélico - por isso, os exemplos citados são marcados com um ponto de interrogação) ou impossível (quando o predicado é télico, marcado com asterisco), tal como mostram as seguintes frases citadas do mesmo autor (modificados por nós pela inclusão de quando), que abrangem proposições:

a) com os atos de fala («Se/quando ${ }^{\star}$ me permite, discordo frontalmente da sua opinião.»);

b) de cortesia («Se/quando? tiveres sede, há cerveja no frigorífico.»);

c) metadiscursivas ( «Se/quando* não estou em erro, a capital da Birmânia é Rankun.»);

d) identificativas ( Se/quando* alguém teve culpa, foi o Presidente da Câmara.»);

e) pleonásticas («Se/quando* não podes ajudar-me, não podes ajudar-me.»);

f) comparativas («Se/quando? o teu filho é irriquieto, o meu é hiperactivo.»).

As orações condicionais, para além da tipologia que acabamos de mencionar, podem ainda ser divididas, de acordo com a base modal dos períodos, em circunstanciais (denominadas também preditivas ou de conteúdo) e epistêmicas, sendo que estas equivalem às não canônicas, e aquelas, ao contrário, às canônicas. A distinção entre as bases modais circunstanciais e epistêmicas baseia-se na teoria de Kratzer (2001), quando se considera uma base modal circunstancial (frase 24) aquela que nos dá resposta à questão que podemos denominar como de controle "o que é que pode acontecer em certas circunstâncias?" e uma base modal epistémica aquela que tem em conta a pergunta "o que será verdade no conjunto das possibilidades?" (frase 25) ${ }^{14}$. Como vemos nos exemplos seguintes, a substituição por quando nem sempre resulta natural:

Se/?quando há um terramoto, este edifício é o primeiro a cair! // Se/?quando houver um terremoto, este edifício é o primeiro a cair!

(25) Se/quando? as luzes \{estão / estiverem $\}$ acesas, é porque está alguém em casa.

\footnotetext{
${ }^{12}$ A autora utilizou o Código penal de Portugal (1982) na versäo atualizada, trabalhando com redações e alterações até a 23 de agosto de 2017.

${ }^{13}$ A autora utilizou o Código penal do Brasil (1940), na versäo atualizada, trabalhando com redações até 10 de fevereiro de 2017.

${ }^{14}$ Agradeço a Rui Marques a disponibilização dos exemplos e das propostas das perguntas de controle.
} 
Para além destes dois tipos, Roxo (2011, p. 139) faz menção à existência das orações condicionais pragmáticas, caraterizadas pela ocorrência do imperativo na frase principal, como se pode ver na seguinte frase: «...se eu estiver equivocado a senhora por favor acuse tá [?]». Na nossa perspetiva, no entanto, estas frases, que se baseiam no plano pragmático-funcional, poderiam ser consideradas também como epistêmicas.

A nossa premissa é que os Códigos Penais respondem à questão "O que é que pode acontecer em certas circunstâncias?" e a presença das orações não canônicas (epistêmicas ou pragmáticas) é obviamente nula, sendo muito pouco provável, num contexto deste gênero, o uso de componentes pragmático-sociais. Antes ao contrário, considera-se como típica dos Códigos a presença das orações condicionais associadas a uma base modal circunstancial (denominada também canônica, preditiva ou de conteúdo), às vezes interpretadas, também, como "condicionais causais“, porque as construções condicionais dos Códigos são um exemplo típico da relação de causa-efeito entre a prótase e a apódose, mais típicas de um texto especializado e científico.

\section{ORAÇÕES TEMPORAIS EM CPP E CPB}

De acordo com as tipologias expostas na seção anterior, tal como temos vindo a antecipar, irão prevalecer, em ambos os Códigos, as orações pseudo-temporais de caráter monocondicional (condição fechada e suficiente) e circunstancial. Relativamente ao tipo de condição, no início, não foi estabelecida nenhuma hipótese e um dos objetivos foi verificar até que ponto coincide a distribuição modotemporal nos dois Códigos.

Começando pela frequência dos conetores, como indicam os resultados da análise quantitativa, visualizados no gráfico 1 , em CPB, as orações pseudo-temporais são introduzidas, quase exclusivamente, pelo conetor quando, sendo em CPP verificadas, também ocorrências do conetor sempre que.
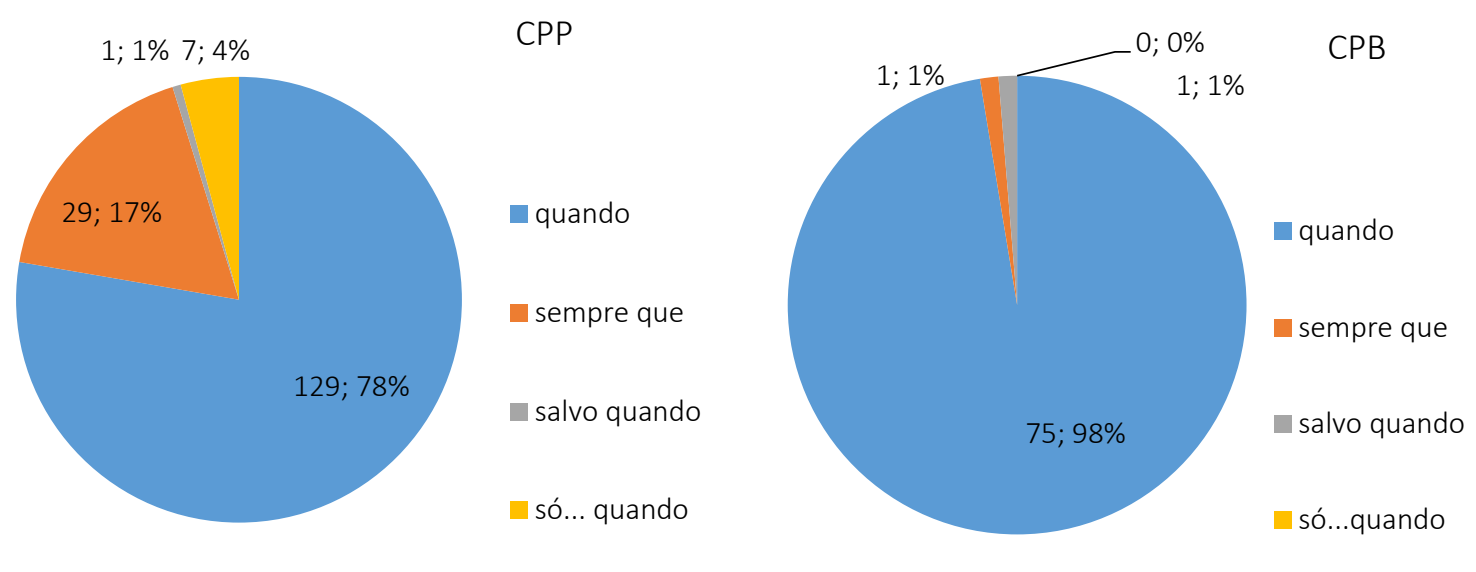

Gráfico 1: Distribuição dos conetores nas frases pseudo-temporais

Fonte: produzido pela autora

Como os exemplos 26-27 mostram, o conetor quando introduz uma frase com proposição hipotética e repetitiva e possui o mesmo valor condicional que o seu homólogo condicional se. Nos Códigos, não foram registados casos em que o conetor quando tivesse uma significação puramente temporal, através da qual colocasse a proposição da oração subordinante em relação temporal de anterioridade, posterioridade ou sobreposição no sentido restrito da palavra. Em todos os casos analisados, com efeito, confirmouse a sua possível substituição por sempre que ou se acompanhado, eventualmente, pelo advérbio de habitualidade ou substituível por sempreque. 
(26) A ação pública é promovida pelo Ministério Público, dependendo, quando a lei o exige, de representação do ofendido ou de requisição do Ministro da Justiça. (BRASIL, 1940, Art. $100 \$ 1^{\circ}$ )

$\downarrow$

A ação pública é geralmente/habitualmente/por regra promovida pelo Ministério Público, dependendo, se a lei o exige, de representação do ofendido ou de requisição do Ministro da Justiça.

(27) Considera-se que há razões de condição de sexo feminino quando o crime envolve

I violência doméstica e familiar;

II menosprezo ou discriminação à condição de mulher.

(BRASIL,1940, Art. 121 VII $§ 2^{\circ}$ )

$\downarrow$

Geralmente/habitualmente/por regra considera-se que há razões de condição de sexo feminino se o crime envolve:

I violência doméstica e familiar;

II menosprezo ou discriminação à condição de mulher. )

No entanto, apesar de a substituição ser viável, não se pode dizer que o traço de temporalidade ceda completamente ao fundo, porque, como vemos nos exemplos extraídos dos Códigos, do ponto de vista lógico, a condição ou proposição da frase subordinada encontra-se sempre num momento anterior à proposição da frase subordinante. Assim, na frase 26, a proposição de a lei o exigir precede à proposição de a ação ser promovida pelo Ministério, não tendo sentido a cronologia inversa nem da mesma frase ( ${ }^{*}$ Quando a ação pública é promovida pelo Ministério Público, dependendo, a lei o exige».). Igualmente, na frase 27 não resulta lógico o sentido inverso $\left({ }^{*}\right.$ «Quando se considera-se que há razões de condição de sexo feminino, o crime envolve I violência doméstica e familiar; II menosprezo ou discriminação à condição de mulher.»)

Partindo da teoria da tipologia das orações condicionais do ponto de vista da base modal veiculada, que divide as orações condicionais em epistêmicas e circunstanciais (canônicas, preditivas ou de conteúdo), nos textos estudados, a interpretação modal de todas as construções pseudo-temporais é, obviamente, circunstancial, sendo, no entanto, as potenciais prótases interpretadas ora como factuais com o predicado no modo indicativo (sobretudo em CPB) ora como hipotéticas (em CPP) com o predicado no modo conjuntivo o que equivale às frases (24), que documentam o valor comum circunstancial com ambos os modos.

De acordo com Hirata (2005), nem um nem outro modo impede a interpretação condicional-temporal de quando. "Percebe-se que os conceitos de certeza e incerteza não podem ser usados como critério de diferenciação entre construções temporais e condicionais, uma vez que, dependendo do contexto de uso, a construção temporal pode implicar incerteza." (HIRATA, 2005, p. 1207), afirmando que para a possível interpretação condicional das construções temporais poderá ser considerado como essencial a natureza aspectual, tal como já se mencinou na seção 2. A mesma interpretação ocorre também em outras línguas, como o italiano ou o inglês:

As construções temporais têm valor condicional quando expressam a habitualidade, que decorre de um valor aspectual, a duração. Os tempos verbais mais usados na interpretação habitual ou habitual-iterativa das construções temporal-condicional são o presente e o imperfeito do indicativo. Esses tempos verbais favorecem o imperfectivo, uma vez que suas constituições temporais internas são ressaltadas. Essas configurações aspectuais e temporais são basicamente as mesmas utilizadas nas construções condicionais preditivas, segundo o que propõe Dancygier (1998), o que permite concluir que as construções temporais com interpretação condicional funcionam como as condicionais preditivas. Além disso, pode-se dizer que também no português as construções temporais recebem uma interpretação condicional quando são usadas com o sentido de "sempre que", como foi mostrado por Traugott (1985) para o inglês e por Visconti (2003) para o italiano."(HIRATA, 2005, p. 1210)

Pelas razões descritas, poderiam ser consideradas como orações temporais com valor condicional também aquelas cujo verbo se encontra no futuro simples e composto do conjuntivo no sentido aspectual repetitivo tanto perfectivo como imperfectivo, tal como mostram os seguintes exemplos, que remetem para a natureza repetitiva da proposição, que ora podem ser substituídos por se, ora por sempre que: 
(28) O tribunal pode dispensar de pena quando:

a) Tiver havido lesões recíprocas e se não tiver provado qualquer dos contendores agrediu primeiro; ou

b) O agente tiver unicamente exercido retorsão sobre o agressor. (PORTUGAL, 1982, Art. 143)

$\downarrow$

O tribunal pode dispensar de pena se/sempre que:

a) houver/há lesões recíprocas e se não provar/prova qualquer dos contendores agrediu primeiro; ou

b) O agente exercer/exerceu unicamente retorsão sobre o agressor.

Como o gráfico 1 indica, no texto português, o uso de sempre que não é raro, opostamente ao Código brasileiro, em que este conetor ocorre apenas esporadicamente, talvez devido à natureza universal de quando.

(29) As penas de interdição, previstas nos incisos I e II do art. 47 deste Código, aplicam-se para todo o crime cometido no exercício de profissão, atividade, ofício, cargo ou função, sempre que houver violação dos deveres que lhes são inerentes.

(BRASIL, 1940, Art. 56)

(30) Sempre que o titular de cargo público, funcionário público ou agente da Administração, for condenado pela prática de crime, o tribunal comunica a condenação à autoridade de que aquele depender. (PORTUGAL, 1982, Art. $66 \$ 5^{\circ}$ )

Como podemos ver, no que se refere à distribuição dos conetores e da tipologia das frases pseudo-temporais, pode ser constatada uma óbvia simetria entre os dois textos comparados. No entanto, quanto à distribuição modotemporal, conforme mostram os seguintes dados do gráfico 2, começa a traçar-se uma linha divisória entre eles. Por um lado, prevalece, em CPB, o uso dos predicados das frases pseudo-temporais no modo indicativo; por outro lado, em CPP, regista-se que a absoluta maioria dos predicados se encontra no futuro do conjuntivo.
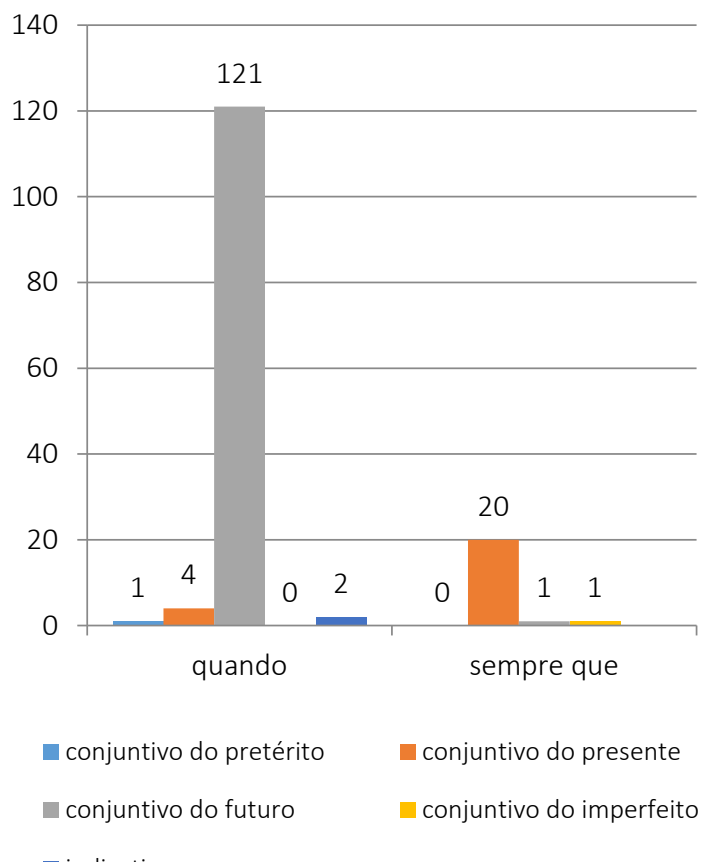

indicativo
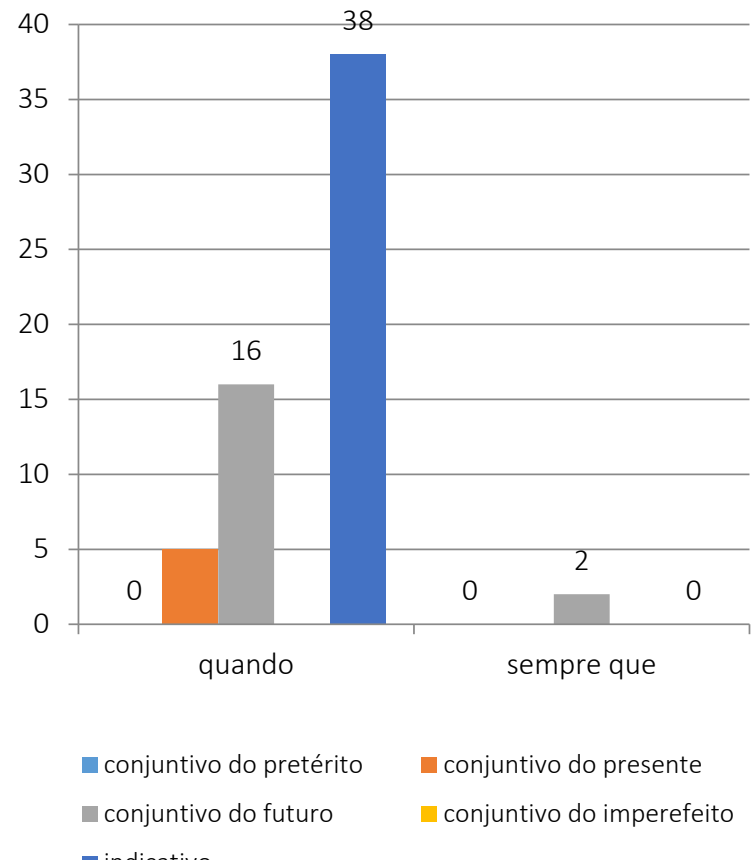

indicativo

Gráfico 2: Distribuição modotemporal nas orações temporais em CPP e CPB

Fonte: produzido pela autora.

A possibilidade de utilizar o indicativo ou o conjuntivo nas orações temporais, de acordo com Marques (1995), pode estar associada à dicotomia modal verdade $v s$. não verdade da proposição, propondo que: “[...] em orações subordinadas temporais, o conjuntivo é 
seleccionado quando não existe a informação de que a proposição é verdadeira, sendo seleccionado o indicativo quando tal informação existe" (MARQUES, 1995, p. 161), como mostra-se nas seguintes duas frases:

a. Quando há reunião da comissão, é enviada uma convocatória aos membros.

b. Sempre que há reunião da comissão, é enviada uma convocatória aos membros.

a. Quando houver reunião da comissão, será enviada uma convocatória aos membros.

b. Sempre que houver reunião da comissão, será enviada uma convocatória aos membros.

Ora, esta dicotomia verdade $v s$. não verdade, existência $v s$. inexistência da informação relativa à proposição da frase pseudo-temporal coincide exatamente com a dicotomia modal existente nas condicionais hipoteticidade $v$ s. factualidade, que traça uma linha divisória entre os Códigos não só no caso das orações que são o objeto da presente análise, mas também, no caso das orações relativas com o antecedente determinado ou no caso das orações adverbiais condicionais quando, em CPB, prevalece o uso do indicativo e, em CPP, ao contrário, o uso do conjuntivo.

Na nossa perspetiva, no Código brasileiro, que abrange, na sua maioria, situações factuais, parte-se das experiências já ocorridas, contando já com a existência de um referente concreto numa cadeia anafórica imaginária, o que justifica o uso do indicativo. Neste aspecto, concorde-se com Marques (1995) quando afirma que estas frases descrevem uma regra e não propriamente a localização temporal de dois estados de coisas. Assim, usando o indicativo, "[...] o enunciador assumiria que já teria existido pelo menos um intervalo de tempo em que a regra fora verificada, o que legitimaria o seu conhecimento da verdade da proposição e a consequente selecção do indicativo." (MARQUES, 1995, p. 163). Isto significa que se já existiu um momento em que foi verificada a a situação descrita no Código, também o Código europeu deveria recorrer ao uso do indicativo nestas frases. No entanto, como os dados verficados indicam, as situações descritas são, em grande medida, consideradas como hipotéticas, sem ser levada em conta a existência de um referente concreto de uma cadeia anafórica potencial que contribua para o caráter verídico da proposição. Usando o conjuntivo, aponta-se para uma possível existência de tais situações no momento posterior ao presente, sendo estas consideradas como hipotéticas, embora não seja tão unívoco como no caso das orações condicionais.

(33) Quando o agente não for declarado inimputável e for condenado em prisão, mas se mostrar que, por virtude de anomalia psíquica de que sofria já ao tempo do crime, o regime dos estabelecimentos comuns lhe será prejudicial, ou que ele perturbará seriamente esse regime, o tribunal ordena o seu internamento em estabelecimento destinado a inimputáveis pelo tempo correspondente à duração da pena. (PORTUGAL, 1982, Art. 104)

São circunstâncias que sempre agravam a pena, quando não constituem ou qualificam o crime. (BRASIL, 1940, Art. 61 i )

Ao mesmo tempo devemos admitir que no Código brasileiro existe uma certa oscilação entre os dois valores modais. Por um lado, vê-se uma evidente tendência para a selecção do modo indicativo; mas, por outro lado, o modo conjuntivo também é, nestas construções, habitual:

(35) Na hipótese deste artigo, quando ao agente tiver sido aplicada pena privativa de liberdade, não suspensa, por um dos crimes, para os demais será incabível a substituição de que trata o art. 44 deste Código. (BRASIL, 1940, Art. $69 \$ 1^{\circ}$ )

No que se refere às formas não finitas, na nossa perspetiva, o valor condicional é visível igualmente no caso das construções com o verbo elíptico, sobretudo adjetivais, como documentam os seguintes exemplos, ou nominais (quando de $+\mathrm{N}$, em $\mathrm{CPB}$ ):

(36) As penas previstas no artigo anterior são, conforme os casos, aplicáveis a quem utilizar os meios previstos no mesmo artigo para, quando encontrado em flagrante delito de furto, conservar ou não restituir as coisas subtraídas.

(PORTUGAL, 1982, Art.. 211) 
(37) O valor da multa será atualizado, quando da execução, pelos índices de correção monetária. (PORTUGAL, 1982, Art. $\left.49 \$ 2^{\circ}\right)$

(38) O plano individual de readaptação social é dado a conhecer ao condenado, obtendo-se, sempre que possível, o seu acordo.(PORTUGAL, 1982, Art. $54 \$ 1^{\circ}$ )

\section{CONCLUSÃO}

Resumidamente, podemos constatar que as orações temporais com um valor condicional na linguagem legal apresentam um caráter universal, descrevendo situações modelares que são ou podem ser iterativas e atélicas. Dessa perspectiva, os textos comparados apresentam uma evidente simetria, sendo, em ambos, prevalecentes as orações introduzidas por quando com valor monocondicional de condição fechada e com a base modal circunstancial. No entanto, relativamente à natureza da condição veiculada, parece que em CPP a maioria das construções encontradas fala a favor de hipoteticidade, expressa pelo conjuntivo, enquanto que em CPB como mais frequente se evidencia a ocorência de condição factual, expressa pelo indicativo.

Conclui-se que as divergências relativas ao uso do modo nas condicionais e nas pseudo-temporais podem ser consideradas como sendo específicas dos Códigos Penais. Uma das explicações que temos para tal conclusão é que, segundo especialistas da área da lei e do direito penal, esta questão poderia ser, teoricamente, relacionada à influência anglosaxónica em CPP e a influência americana em CPB. No entanto, não tendo encontrado referências bibliográficas sólidas que possam sustentar tal tese, deixamos esta questão em aberto para possíveis estudos futuros.

Do ponto de vista linguístico, o futuro do conjuntivo na prótase mostra que o evento/estado de coisa, referente ao domínio do fato julgado (domínio local), pode ser semanticamente concebido como algo provável, e retrata um tipo de não-assertividade baseado na falta de evidências diretas quanto à realização do evento descrito na prótase. Aplicando esta tese à análise contrastiva dos Códigos Penais, na versão portuguesa, as construções condicionais com o futuro do conjuntivo pragmaticamente implicam a não existência do agente concreto do crime, não sendo excluída, no entanto, a sua existência hipotética no futuro. Concebe-se, por isso, o seu conteúdo como algo provável, potencial e hipotético, tal como mostra o esquema 4. Ao contrário, o Código brasileiro, em nossa perspetiva, parte da existência de um referente precedente e, talvez, igualmente, da atualização do conteúdo do Código no momento de ser julgado o crime, que tal como o seu agente é identificado no momento da leitura e da aplicação das penas tal como mostra o esquema 5. Deste ponto de vista, o Código português poderia ser caraterizado pelo valor modal hipotético, enquanto que o Código brasileiro favorece a modalidade factual.

Esquema 4: Interpretação hipotética das orações condicionais em CPP

$\begin{array}{cc}\text { Presente } & \text { Futuro } \\ \text { Leitura do Código } & \text { identificação do agente e do crime }\end{array}$

Esquema 5: Interpretação factual das orações condicionais em CPB

Presente

Leitura do Código

II

Identificação do agente e do crime 
Do ponto de vista da perceção do valor modal hipoteticidade vs. factualidade por parte do leitor do Código, no entanto, os dois modos não refletem a supradita dicotomia, percebendo o leitor dos Códigos todas as disposições como hipotéticas, indepdentemtente de ser usado o conjuntivo ou o indicativo.

\section{REFERÊNCIAS}

BRASIL. Código Penal do Brasil. Decreto-lei n. ${ }^{\circ} 2.848$, de 7 de dezembro de 1940. Código Penal. Disponível em: <http://www.planalto.gov.br/ccivil_03/decreto-lei/Del2848compilado.htm>. Acesso em: 10 fev. 2017.

DAMIÃO, R.; HENRIQUE, A. Curso de português jurídico. São Paulo: Atlas, 2007.

DANCYGIER, B., SWEETSER, E. Constructions with if, since and because: causality, epistemic stance and clause order. In: COUPER-KUHLEN, E.; KORTMANN, B. (Ed.). Cause, concession, contrast, condition: cognitive and discourse perspectives.ed. Mouton de Gruyter, Berlim, 2000. p. 111-142

HIRATA-VALE, F. B. A expressão da condicionalidade no português escrito do Brasil: continuo semântico-pragmático. 2005. $149 f$. Tese de doutorado (Doutorado em Letras, Lingüística e Língua Portuguesa)- Faculdade de Filosofia, Ciências e Letras, UNESP, Araraquara, 2005.

KRATZER, A. Modality. In: VON STECHOW, A; WUNDERLICH, D. (Org.). Semantics. Berlim: Gruyter, 1991.p. 639-650.

LOPES, A.C.M. Contributos para o estudo de construções condicionais não canónicas em Português europeu contemporâneo. Diacrítica, Ciências da Linguagem. Revista do Centro de Estudos Humanísticos. Universidade do Minho, Portugal, n. 23, p. 149170, 2009.

LOBO, M. Subordinação adverbial. In: RAPOSO, E.B.P. (Org.). Gramática do Português. v.II. Lisboa: Fundação Calouste Gulbenkian, 2013. p. 1901-2057.

MARQUES, R. Sobre o valor dos modos conjuntivo e indicativo em português. 1995. 177f. Dissertação (Mestrado em Linguística Portuguesa Descritiva) - Faculdade de Letras, Universidade de Lisboa, Lisboa, 1995.

- Variações de forma e sentido em construções condicionais. Actas do XIV Encontro Nacional da Associação Portuguesa de Linguística. Braga: APL, 1999. p. 219-238.

O modo em condicionais contrafactuais e hipotéticas. Actas do XVI Encontro Nacional da Associação Portuguesa de Linguística. Lisboa, APL, 2000. p. 349-361.

Sobre a distribuição do modo em PE e em PB. Actas do XVI Encontro Nacional da Associação Portuguesa de Linguística. Lisboa: APL, 2001. p. 699-713.

.On the system of mood in European and Brazilian Portuguese. Journal of Portuguese Linguistics, v. 3, n. 1, p. 89-109, 2004.

Modalidade e condicionais em português. ReVeL, v. 12, n. 8, p. 106-130, 2014.

PERES, J. A.; MÓIA, T.; MARQUES, R. Sobre a forma e o sentido das orações condicionais em português. In: FARIA, I. H. M. (Org.). Lindley Cintra, homenagem ao homem, ao mestre e ao cidadão. Lisboa: Cosmos, Faculdade de Letras da Universidade de Lisboa, 1999. p. 627-653. 
PORTUGAL. Código Penal de Portugal. Decreto-Lei no 400/82, de 23 de setembro. Disponível em: <www.codigopenal.pt>. Acesso em: 23 ago 2017.

RAMOS, J. C. Introdução ao português jurídico. Praga: Karolinum, 2012.

RAMOS, J .C. Ocorrência e interpretação dos verbos modais 'dever' e 'poder' em contexto jurídico: contributos para uma análise juslinguística. 2017. 207f. Tese (Doutorado em Linguística Aplicada) - Faculdade de Letras da Universidade Carolina, Praga, 2017.

ROXO, M do R. Condutas sociais em construções condicionais preditivas, epistêmicas e pragmáticas no discurso jurídico oral. Estudos Linguísticos, São Paulo, v. 40, n. 1, p. 133-142, 2001.

SANTOS, D. Português internacional. In: TEIXEIRA, J. (Ed.). O português como língua num mundo global: problemas e potencialidades. Centro de Estudos Lusíadas da Universidade do Minho, 2016. p. 51-68.

SANTOS, D. (Org.). Corpus Linguateca. 2017. Disponível em: <www.linguateca.pt>. Acesso em: 20 ago. 2017.

SVOBODOVÁ, I. Sintaxe da língua portuguesa. Universidade de Masaryk. Brno. República Tcheca: UniPress, 2014.

SWEETSER, E. From Etymology to Pragamatics, Metaphorical and cultural aspects of semantic structure. Cambride University Press, Cambridge, 1990.

TRAUGOTT, E. C. Conditional markers. In: HAIMAN, J. (Ed.). Iconicity in syntax. ed: John Benjamins, Amesterdão, 1985. p. 289307.

XAVIER, R. Português no direito. Rio de Janeiro: Forense, 2006.

ZAEFFERER, D. Conditionals and unconditionals: Cross-linguistic and logical aspects. In: emantic universals and universal semantics. Berlim: Dietmar Zaefferer, 1991. 